\title{
IMPLICATIONS FOR SHALLOW LAKE MANIPULATION: RESULTS OF AQUARIA AND ENCLOSURE EXPERIMENTS MANIPULATING MACROPHYTES, ZOOPLANKTON AND FISH
}

\author{
ZUCCARINI, P. ${ }^{1 *}-$ CIURLI, A. ${ }^{1}-$ AlPI, A. ${ }^{1}$ \\ ${ }^{1}$ Università di Pisa, Dipartimento di Biologia delle Piante Agrarie, Sezione Fisiologia \\ Vegetale, Via Mariscoglio 34, 56124, Pisa, Italy \\ *Corresponding author \\ e-mail:p.zuccarini@virgilio.it \\ (Received 20 ${ }^{\text {th }}$ October 2010; accepted $14^{\text {th }}$ March 2011)
}

\begin{abstract}
The Massaciuccoli Lake, a 700 ha shallow lake, located in the Migliarino San Rossore Massaciuccoli Natural Park, along the Tuscan coast (Italy), has undergone a dramatic reduction of the macroalgal and submerged macrophytic communities over the last fifty years. This reduction was both in terms of the number of species and abundance, leading in recent years to a turbid water-phytoplankton dominated state and to the disappearance of submerged macrophytes. The aim of this study was to investigate, in aquaria experiments, the minimum threshold of light, necessary for the survival of a macrophyte, Myriophyllum verticillatum L., caused by sediment resuspension. Subsequently enclosure experiments were carried out with biomanipulation techniques (such as the removal of the fish community, the inoculation of zooplankton, Daphnia magna Strauss and forced reintroduction of the macrophyte) in enclosures. The results showed that, currently, the PAR intensity at the bottom of the lake is not sufficient to allow spontaneous recovery of the submerged vegetation. The positive effect of biomanipulation, due to fish removing plankton and phytoplankton-grazing, may lead to a significant clarification of the water column in the treated enclosures, allowing radication and growth of submerged vegetation. Nevertheless, an effective recovery of Massaciuccoli Lake is not likely to be achieved until an integrated approach (ranging from the reduction of the pollutant sources to partial dredging of the sediment, because of the high nutrient levels), is performed.
\end{abstract}

Keywords: restoration, shallow lakes, aquatic macrophytes, biomanipulation, enclosures

\section{Introduction}

The number of aquatic ecosystems contaminated by anthropogenic-derived pollutants is at present increasing. Human activity adds excessive amounts of plant nutrients (primarily phosphorus, nitrogen, and carbon) to streams and lakes in various ways. Runoff from agricultural fields and breeding, industrial chemicals, urban lawns and domestic sewage, are the principal sources of these nutrients. This enrichment (notably in $\mathrm{N}$ and $\mathrm{P}$ ) above natural levels is traditionally defined as eutrophication. This "nutrient pollution" problem represents the most important water quality problem worldwide (Harper, 1992; Lau et al., 2001). The enrichment causes an increase in the net primary productivity of ecosystems and an associated decline of water quality. Compared with deep-water lakes, shallow lakes tend to be more prone to eutrophication as they have a smaller dilution capacity (Lennox, 1984).

Changes in nutrient loading are probably a major reason why the stability properties of shallow lakes have changed. At low nutrient levels the system has one globally stable equilibrium, a clear-water state. If the nutrient level is raised further the stability of the clear state decreases, and slight perturbations are enough to cause a switch to the turbid equilibrium. These nutrients also proved to be powerful stimulants to an excessive algal 
growth, or "blooms" of algae. The algal blooms led to competitive interactions with submerged plants that are largely disappearing (Moss et al., 1996a). Submerged aquatic macrophytes are important because they stabilize the macrophytes-dominated state by increasing water transparency and the environmental quality of shallow lakes (Carpenter and Lodge, 1986; Jeppesen et al., 1998; Scheffer, 1998). Macrophytes reduce nutrient levels and sediment resuspension, they provide shelter for zooplankton and young fish and a habitat for macro-invertebrates. Macrophytes also permit the physical stabilization of the bottom and can excrete allelopathic substances that inhibit the growth of other photoautotrophs, such as epiphyton and phytoplankton (Scheffer et al., 1993; Lauridsen et al., 1996; Petrini et al., 1996; Scheffer, 1998; Van Donk and Van de Bund, 2002; Mulderij et al., 2003; Mulderij et al., 2005; Mulderij et al., 2007). Submerged plants affect their environment, but obviously the environment also has an effect on the plants. This positive feedback is thought to cause alternative stable states in shallow lakes. So a lake can be in one state or another within a certain range of nutrient concentrations. This phenomenon is important for lake management as the shift from turbid to clear water is expected to occur at much lower nutrient levels than the opposite shift, a process called "hysteresis" (Scheffer et al., 1993).

Restoration of eutrophic lakes in their turbid water-phytoplankton dominated state, presents several difficulties and the most important is associated with the long termphosphorus release from the sediments (Jeppesen et al., 1990; Pitt et al., 1997; Søndergaard et al., 2002). Due to this phenomenon, many attempts at restoring eutrophic lakes by means of reduction of the nutrient loading, have given unsatisfactory results, since high values of phosphorus concentration in the water column have been observed for long periods following the intervention (Scheffer et al., 1993; Phillips et al., 1994). Moreover, in many cases, nutrient removal from sources such as very large lakes can be too expensive, and nutrient loading control from agricultural areas can be difficult since there is not usually a restricted source.

These difficulties in restoration caused the efforts of researchers to focus on the use of biomanipulation techniques as an alternative and more controllable tool (Drenner and Hambright, 1999). Biomanipulation was introduced as a lake-restoration technique that focused on trophic-cascade top-down effects (Shapiro et al., 1975). Many articles confirm the positive effects of biomanipulation (Jeppesen et al., 1990; DeMelo et al., 1992; Meijer et al., 1994; Hansson et al., 1999; Drenner and Hambright, 1999; Meijer et al., 1999). The idea is to control fish and zooplankton communities (substantial reduction of the overwintering planktivorous and benthivorous fish stock that causes large filter-feeding zooplankton). This action exerts a higher grazing pressure on phytoplankton, thus forcing a spring clear water phase. Reduction of benthivorous fish further supports the clearing of the lake, because it reduces the resuspension of the sediment and the release of nutrients in the water due to these bottomfeeders (Breukelaar et al., 1994; Havens, 1993). Clear water, during spring, allows the submerged vegetation to grow and creates a stable clear water state (Hosper and Meijer, 1993; Hosper, 1997; Hosper et al., 2005). The achievement of a total macrophyte recovery actions would be required on several fronts, ranging from the drainage of the sediment to the reduction of the nutrient charge (Berklioglu et al., 1999; Meijer et al., 1999).

In this paper we relate to Massaciuccoli Lake, an eutrophic shallow lake in Central Italy where a constant and progressive reduction of the macroalgal and submerged macrophytic community (such as Chara spp., Potamogeton pectinatus L., Potamogeton 
crispus L., Ceratophyllum demersum L., Utricularia vulgaris L., Myriophyllum verticillatum L., Elodea canadensis Michaux) has been shown to occur over the last 50 years (Brunelli and Cannicci, 1942; Pedreschi, 1956). Over the last 10 years a continuous reduction of submerged macrophytes has occurred (Tomei et al., 1997) which resulted in only two species remaining (M. verticillatum and E. canadensis) which have now recently disappeared (Ciurli et al., 2008). Extensive research was carried out in this lake to identify the turbid water state and eutrophication conditions (Ceccarelli et al., 1997; Cuppen et al., 1997). The turbidity of water does not provide sufficient irradiation for plants at the lower levels of the water column (Ciurli and Alpi, 1999). Turbidity is due to several factors: 1) suspension of minute particles brought about by the erosion of agricultural soils located all around the lake (Pensabene et al., 1997), 2) the phytoplankton-dominated state due to the excess of nutrients, brought about by emissaries (Mason, 1997), 3), sediment re-suspension by crayfish, Procambarus clarckii Girard (Gherardi, 1999; Barbaresi and Gherardi, 2001), 4) loss of cohesion of the bottom due to the absence of radicated plants (Schutten et al., 2005).

In the current paper we investigated the macrophytes recovery potential, using the model species $M$. verticillatum L., through in vitro tests (tests in aquaria) and in vivo tests, practicing biomanipulation techniques in enclosures/exclosure experiments in a lake. We have chosen this plant because, together with E. canadensis, it has been the last to disappear. $M$. verticillatum, shows the best capacity to colonise the aquatic environment due to its tendency toward lengthening, and generally showed more remarkable results than $E$. canadensis in reducing nutrient content in water, particularly regarding nitrogen, showing phytodepuration capacity (Ciurli et al., 2008).

The final aim of the research was to obtain evidence for the possibility of the recovery of aquatic macrophytes, and for their important role in the equilibrium of the lake.

Considering that the ultimate goal is the reintroduction of macrophytes in the lake, the intermediate objective is to understand how such plants could grow in lake water. The working hypotheses are: 1) to assess the feasibility of the growing macrophyte $M$. verticillatum, in aquaria filled with water and sediment lake. 2) characterize, in aquaria, the minimum threshold of light necessary for the survival of the macrophyte. 3) try to carry out the biomanipulation, in enclosures, not accompanied by $\mathrm{P}$ load reduction. The results obtained by testing of the above-mentioned hypotheses could be important for the forced reinsertion of submerged vegetation in the whole lake after the causes of degradation have been removed.

\section{Materials and methods}

The model species was $M$. verticillatum L., collected in a small stream flowing into the lake in the "Piaggetta" zone, where submerged vegetation is still present. Scions were collected by cutting the apical part of the plant, and were carefully washed to remove mud and algae before placing them into the propagation aquaria.

\section{In vitro test}

\section{Aquaria preparation}

Two aquaria systems were prepared: as plant propagation (to obtain more working material), as investigation about the minimum survival light threshold of $M$. 
verticillatum, caused by resuspension of sediment (to perform turbidity tests). Five propagation aquaria of 2001 capacity (with dimensions $40 \times 100 \times 50 \mathrm{~cm}$ ) were prepared, with a layer $(10 \mathrm{~cm})$ of aqualite (Aqualine $\left.{ }^{\circledR}\right)$ and an upper layer $(5 \mathrm{~cm})$ of fine gravel filled with tap water. The filtration system consisted of a pump with a submerged filter, with a 4001 flow per hour. The lighting plant was composed, for each aquarium, of two fluorescent Dennerle lamps (Trocal 3085, $30 \mathrm{~W}$ ) with reflecting parabola, connected with a timer set on 10 hours of light per day. The temperature was kept at 18$20^{\circ} \mathrm{C}$ with a $150 \mathrm{~W}$ immersion heater. The plant scions did not show transplant shock and were periodically trimmed to keep them at a constant length of about $30 \mathrm{~cm}$.

\section{Aquaria experiment}

Each aquarium had three replicates and the experiments were repeated many times in one year of experimentation in the laboratory. This was possible because the experiments were carried out in growth chamber in controlled conditions. The aquaria used for the turbidity tests were smaller $(25 \times 30 \times 33 \mathrm{~cm})$ with a 301 capacity, totally covered with black film to stop natural light. They were filled with water and sediment collected in three different parts of the lake: Central Lake (CL), Foce Barra (FB) and Centro Chiaro (CC) whose sediment chemistry is reported in Table 1. The samples of water and sediment were put into opaque plastic containers to protect them from the natural light, and directly brought to the laboratory for the preparation of the aquaria. Chemical analyses (ammoniacal, nitrous, nitric and total nitrogen, orthophosphate and total phosphorus) of these waters and sediments were performed according to the procedures indicated in (APHA, 1998) in order to put the results in correlation with different plant growth responses.

10 plant scions per aquarium (corresponding to the density of 80 unit $^{-2}$, data obtained from experimental preliminary tests) of $10 \mathrm{~cm}$ length (obtained from the pruning of propagation aquaria plants) were placed at the bottom of the aquaria. The lighting system for each aquarium consisted of one single fluorescent Dennerle lamp, connected to a timer set on 10 hours of light per day. Aquaria were totally covered with black film to stop natural light. The irradiation in each aquarium was measured daily at $15 \mathrm{~cm}$ depth using an aquatic Quantometer Radiation Sensor (Li-Cor) in order to determinate the PAR (Photosynthetically Active Radiation). Since our intention was to simulate the natural lake conditions, different light intensities, in aquaria, were artificially reproduced through constant lighting (except for the control in the dark) and through sediment re-suspension (instead of artificial shading) using pumps which raised the sediment. The pump was placed with the rotor near the bottom in order to prevent disturbance of the water-air interface and so avoid uncontrolled extra-oxygenation of the water column, and detached sufficiently to prevent shading from silt on the leaves. The five cases were: 1) aquarium completely dark (dark control, corresponding to PAR of the lake bottom $3 \mathrm{~m}$ ), 2) maximum turbidity (corresponding to $60-50 \mathrm{~cm} \mathrm{depth}$ ), 3) medium turbidity (50-30 cm depth), 4) minimum turbidity $(30-15 \mathrm{~cm})$ and 5) no turbidity (light control, with the pump switched off) (Table 2). Extra care was taken in placing the pumps to prevent the water flux from causing mechanical stress to the plants. Height and fresh and dry weight were measured for every plant at every treatment, at the beginning and at the end of the trial, which lasted 4 weeks. 
Table 1. Water and sediment chemistry of the three different sampling sites of Massaciuccoli Lake $(*$ the values were under the lower limit of determinability)

\begin{tabular}{cl|l|l|l}
\hline & & Centro Lago & Foce Barra & Centro Chiaro \\
\hline & Water & 10.36 & 11.48 & 2.94 \\
$\mathbf{N O}_{2}-\mathbf{N}(\mu \mathrm{g} / \mathrm{l})$ & Sediment & 5.07 & 7.12 & 4.96 \\
& Water & 26.18 & 37.24 & 21.42 \\
$\mathbf{N O}_{3}-\mathbf{N}(\mu \mathrm{g} / \mathrm{l})$ & Sediment & 30.27 & 71.80 & 40.05 \\
& Water & 129.92 & 173.46 & 37.80 \\
$\mathbf{N H}_{\mathbf{3}} \mathbf{- N}(\mu \mathrm{g} / \mathrm{l})$ & Sediment & 119.00 & 75.40 & 120.23 \\
& Water & 3647.00 & 2262.26 & 696.08 \\
$\mathbf{T o t a l}_{\mathbf{N}} \mathbf{N}(\mu \mathrm{g} / \mathrm{l})$ & Sediment & 7.68 & 7.93 & 20.39 \\
& Water & $<6.2^{*}$ & $<6.2^{*}$ & $<6.2^{*}$ \\
$\mathbf{P O}_{4}-\mathbf{P}(\mu \mathrm{g} / \mathrm{l})$ & Sediment & 51.73 & 48.61 & 142.42 \\
& Water & 52.39 & 81.84 & 41.85 \\
$\mathbf{T o t a l}_{\mathbf{P}}(\mu \mathrm{g} / \mathrm{l})$ & Sediment & 780.35 & 819.68 & 1161.20 \\
\hline
\end{tabular}

\section{Description of site studied}

The Massaciuccoli Lake, with an extension of 700 ha, is located in the northern part of the Migliarino San Rossore Massaciuccoli Natural Park, $10 \mathrm{~km}$ north of Pisa (Italy), lat. $43^{\circ} 50^{\prime} 14$ ', long. $10^{\circ} 21^{\prime} 39^{\prime \prime}$ (Fig. 1). The lake and the surrounding wetlands cover about 2700 ha of the territory of the Natural Park. They represent the widest wetland area along the Tuscan Coast and they have obtained national and international importance for their flora and fauna communities. The lake is located $4 \mathrm{~km}$ from the sea, 0 meters above sea level, and it is classified as a shallow lake as its average depth is $2.5-3 \mathrm{~m}$ (Scheffer, 1998).

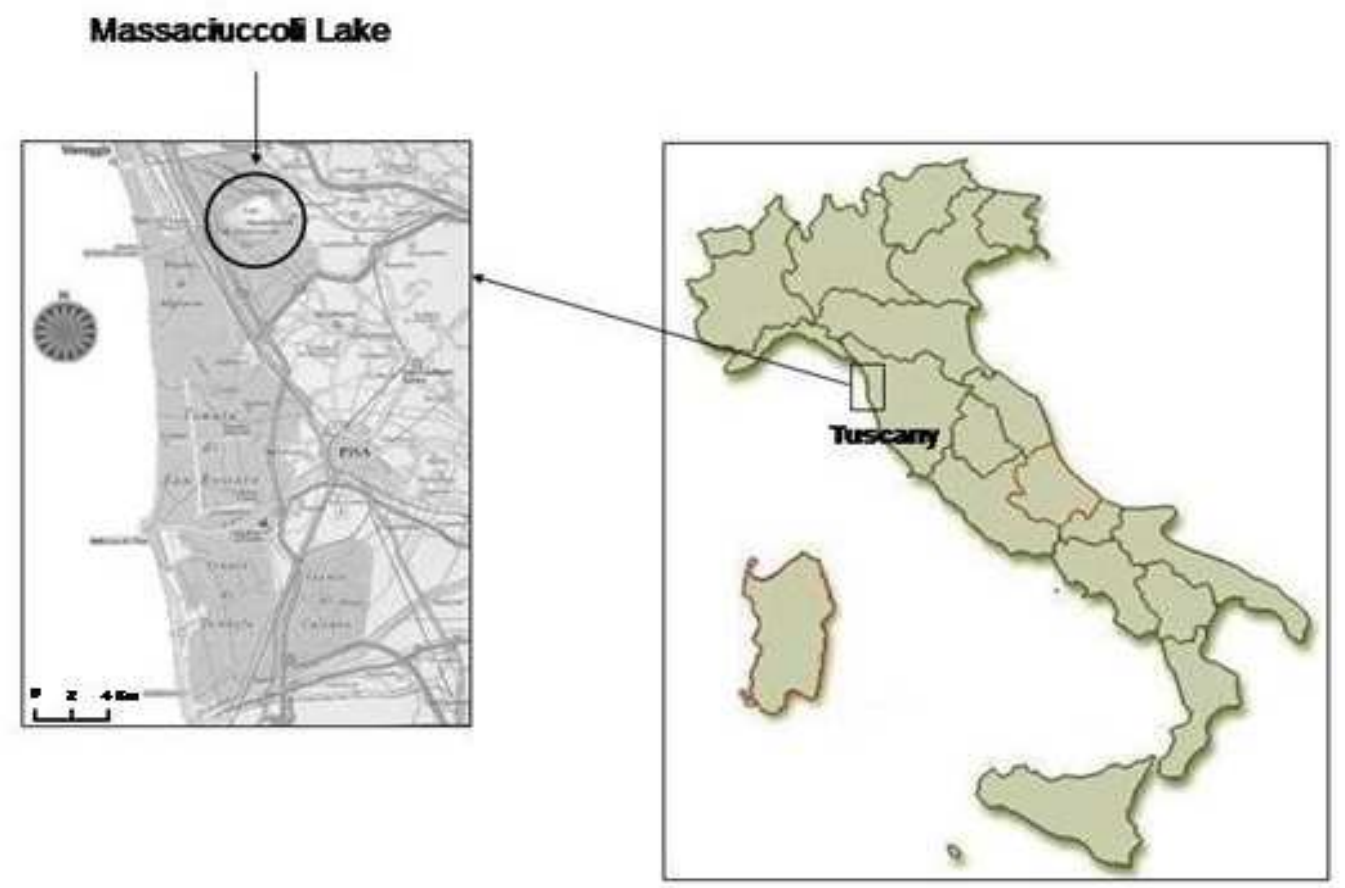

Figure 1. Location of the experimental area 


\section{In vivo tests:enclosure/exclosure experiments}

It was not possible to carry out a project involving biomanipulation, whether or not accompanied by $\mathrm{P}$ load reduction, in the whole of the shallow lake due to poor financing, thus an attempt at biomanipulation was made in enclosures. Nine cylindrical enclosures, $3 \mathrm{~m}$ high and with a diameter of $6 \mathrm{~m}$, indicated as A1, 2, 3, B1, 2, 3, C1, 2, 3, were placed in an area of the lake where the water depth is about $2 \mathrm{~m}$, called Punta Grande (PG). The enclosures were open cylinders of small-meshed plastic net $(350 \mu \mathrm{m}$ diameter), so as to prevent zooplankton from escaping to the outside, but at the same time enable water to flow freely. Their upper part was fixed to a floating plastic ring, protruding $50 \mathrm{~cm}$ out of the water in order to prevent the entrance of fish and crayfish. The lower parts of the enclosure were fixed to a heavy chain, sunk into the sediment for more then one meter, so that the mesocosmos were totally isolated. Fish were removed in winter from all the enclosures with an electrostunner. A trap was placed in every enclosure and controlled weekly to capture the possible fish or crayfish. Afterwards, in Spring, the zooplankton inoculum (about 5000 individuals of D. magna) was added to the enclosure A replicates; the inoculum had been raised in a rain-water basin in the Department of Crop Biology. The pre-existing zooplankton community in the water of Centro Chiaro was considered not influential because of its scarcity (Baldaccini et al., 1997). Zooplankton was periodically monitored through collection with a tube $(180 \times$ $10 \mathrm{~cm}$ diameter) by filtering 141 of water through a plankton net (mesh size $100 \mu \mathrm{m}$ ); samples were preserved in a solution of $40 \mathrm{~g}^{-1}$ sucrose and $4 \%$ formaldehyde (Haney and Hall, 1973) until counting. The experimental scheme consisted in the application of biomanipulation in the three A replications, no experiments in the three $\mathrm{B}$ replications, which represented enclosure controls, and reinsertions of plants without biomanipulation in $\mathrm{C}$ replications, which represented the biomanipulation controls.

Zooplancton communities in the A enclosure replicates showed marked changes in water transparency compared to the open lake water (exclosure) and to B and C replicate enclosures, even if the lake bottom view in enclosures was not achieved. Plants were placed in $\mathrm{A}$ enclosure and $\mathrm{C}$ enclosure replicates in June, when in the three $\mathrm{A}$ enclosure replicates (where biomanipulation had been made) the value of Secchi depth was $70 \mathrm{~cm}$, light intensity was $600 \mu \mathrm{mol} \mathrm{s}{ }^{-1} \mathrm{~m}^{-2}$ and chlorophyill-a was $3 \mu \mathrm{g} \mathrm{l}^{-1}$ (see results). $15 \mathrm{~cm}$ scions of $\mathrm{M}$. verticillatum, taken from the above-mentioned propagation aquaria, were tied to $0.5 \mathrm{~m}^{2}$ nets with $1 \mathrm{~cm}$ mesh. The nets with the plants were maintained floating in water at three different depth levels: water surface, $30 \mathrm{~cm}$ and 1.5 $m$ of depth. To keep the depth the nets were tied to a floating cork on top and to a lead weight at the bottom. Different light levels, the same as in the aquaria were obtained by the placement of the macrophyte scions at different depths in the water column in enclosures where biomanipulation techniques had been applied (Table 3). The plant scions at each level were 30 . Height and dry weight of the macrophytes were measured at the beginning and at the end of the trial as in the laboratory experiment.

During the experimental period from May to August the following elements were measured: $\mathrm{pH}$ (portable membrane pH-meter, model HI 8314, Hanna Instruments), electrical conductivity (conducimeter model HI 8733, Hanna Instruments), dissolved oxygen and temperature (OX 22, Aqualytic), transparency (Secchi disc); PAR (Photosynthetically Active Radiation) irradiation (Quantometer Radiation Sensor, LiCor), chlorophyll-a (measured through spectrophotometric way). Samples were taken from the central part of Massaciuccoli Lake (three replicates for each sample), inside each enclosure and exclosure (APHA, 1998). 
Measurements were performed around 12:00 h, at the hour of the day associated with maximum irradiation. The aquaria test lasted two years and started one year before experiments in the lake. The preparation before plants were planted was about 1 month, and the enclosure/exclosure was replicated for three years.

\section{Statistical analyses}

Two-way Anova with interaction was used to test for differences between watersediment combinations and between light regimes in the turbidity experiment, in which the average of the ten plants of each aquarium was considered as one replicate; a test for heteroschedasticity was run to confirm the homogeneity of variance among the different aquaria. One-way Anova was used to test for differences between different depth levels in the enclosures experiment, followed by Tukey's Honestly Significant Difference test. Significance in the differences between the trends of chemical-physical parameters was investigated by comparing $95 \%$ C.I. error bars referred to the repeated measurements.

Statistical analyses were run with R@ software (R Development Core Team, 2005), graphical elaboration was made with Graph Pad@.

Table 2. Five cases of different turbidity levels in the aquaria, obtained by changing the pump flow. The light intensity equivalent to 0 was obtained maintaining the aquarium completely dark without lamp, the other values of light intensity were obtained using one lamp per aquarium but with different turbidity levels

\begin{tabular}{|c|c|}
\hline Turbidity level & Light intensity $\left(\boldsymbol{\mu} \mathbf{m o l ~ s}^{-1} \mathbf{~}^{-2}\right)$ \\
\hline Completely dark & 0 \\
\hline Maximum turbidity & 20 \\
\hline Medium turbidity & 30 \\
\hline Minimum turbidity & 36 \\
\hline No turbidity & 54 \\
\hline
\end{tabular}

\section{Results}

\section{Aquaria experiments}

The comparison between the growth of $M$. verticillatum in the three different watersediment systems shows very highly significant differences in growth responses depending on the sampling site ( $\mathrm{p}<0.001$, one-way ANOVA) (Fig. 2). Plants grown on sediment and water from Centro Chiaro (CC) reached the greatest heights even at the lowest light levels $\left(20 \mu \mathrm{mol} \mathrm{s} \mathrm{s}^{-1}\right)$, because of lengthening. If we consider the accumulation of dry mass, the best results were obtained by plants grown on the Centro Lago (CL) system (water and sediment), mainly at the highest light levels. Plants grown on the Foce Barra (FB) system represent an intermediate situation between the two former ones, showing generally lower growth levels.

Different light levels are also associated with highly significant different growth levels $(\mathrm{p}<0.01)$. In general, plants show the best growth results not only at maximum, but also at medium light levels $\left(30-36 \mu \mathrm{mol} \mathrm{s}^{-1} \mathrm{~m}^{-2}\right)$, giving reason to hope for a good recovery potential also in field experiments. The effect of the combination of light regime and type of water and sediment is highly significant too in causing different growth responses $(\mathrm{p}<0.01)$. 

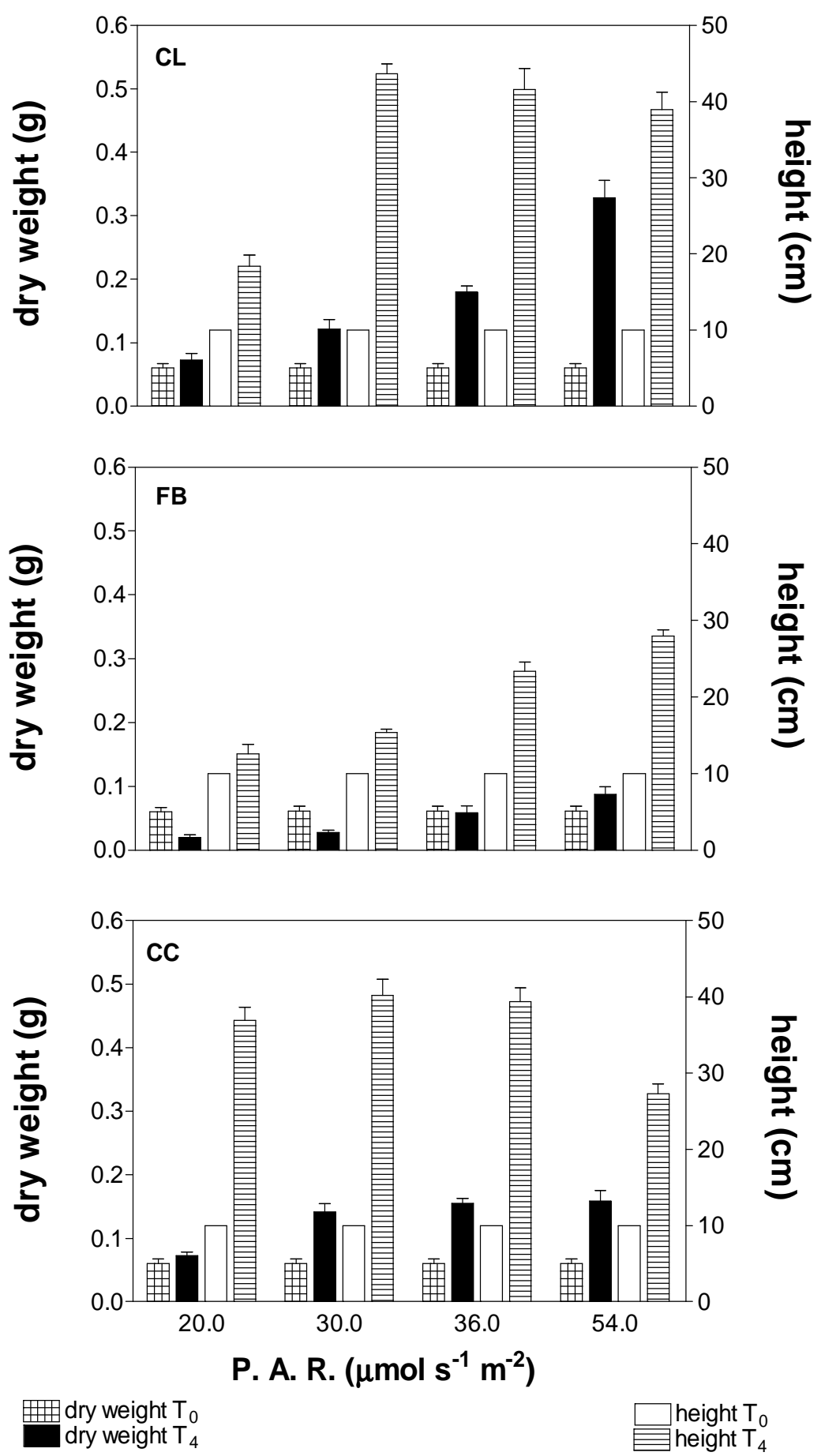

Figure 2. Growth performances (dry weight and height) of Myriophyllum verticillatum L. in water and sediment systems from three different sites of the Lake (named Centro Lago, CL;

Foce Barra, FB; Centro Chiaro, CC) at different irradiation levels, at the beginning $\left(T_{0}\right)$ and at the end $\left(T_{4}\right)$ of the experiment, after four weeks. In TO the height of all the plants was $10 \mathrm{~cm}$ and the dry weight 0,06 $\mathrm{g}$ as it is possible to observe in the figure. The bars represent the mean and standard error out of three replicates of ten plants each 


\section{Enclosure experiments}

At the end of the experimentation, plants from three A enclosure replicates showed an average $50 \%$ rate of survival at $1.5 \mathrm{~m}$ depth, $100 \%$ at $30 \mathrm{~cm}$ and $100 \%$ above the surface (Fig. 3); plants from enclosures C (without biomanipulation) had all disappeared.

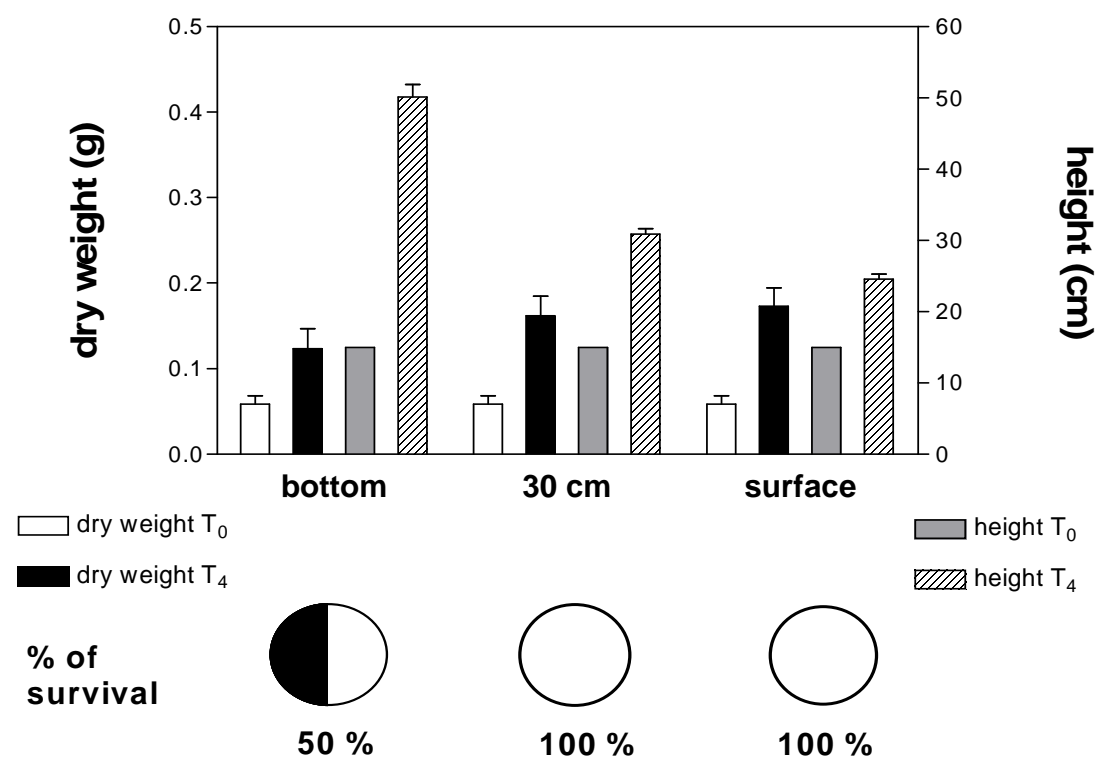

Figure 3. Average growth and \% survival of plants grown in three enclosure A replicates at different depth levels: bottom of the lake (1,5 m of depth, $30 \mathrm{~cm}$ of depth and surface of the water). The bars represent the mean and standard error out of thirty plants replicated twice

In A enclosure replicates, plant scions at $1.5 \mathrm{~m}$ reached the highest values of height, while the minimum height was shown by the scions above the surface. Very highly significant differences ( $\mathrm{p}<0.001$, one-way ANOVA) of height increases were related to the different depth levels; Tukey's test indicated the pair surface- $1.5 \mathrm{~m}$ as the source of maximum diversity $\left(\mathrm{p}=1,0^{*} 10-7\right)$. On the contrary, plants grown at $1.5 \mathrm{~m}$ showed minimum dry biomass production, with significant differences $(\mathrm{p}<0.05)$ compared to plants at the surface.

Secchi depth and PAR irradiation (measured at $30 \mathrm{~cm}$ depth) remarkably differed among the three sets of enclosures and the two open water sampling sites (Punta Grande and Centro Lago, exclosure) (Fig. 4). In A replicates, in particular, Secchi depth and PAR irradiation increased sharply during the first two months, and decreased in the second part of the experiment. The maximum clarification of water was reached in A replicates at the end of June, when Secchi depth was about $70 \mathrm{~cm}$ and PAR irradiation was $600 \mu \mathrm{mol} \mathrm{m} \mathrm{m}^{-2} \mathrm{~s}^{-1}$; these values successively dropped down to $35 \mathrm{~cm}$ and $300 \mu \mathrm{mol}$ $\mathrm{m}^{-2} \mathrm{~s}^{-1}$, respectively, at the end of August. In B and C enclosure replicates the values of Secchi depth and PAR irradiation were significantly lower than in A replicates ( $p<0.001$ ), the transparency fluctuating between 30 and $50 \mathrm{~cm}$ in $\mathrm{B}$ and between 40 and $55 \mathrm{~cm}$ in $\mathrm{C}$; the light intensity was between 250 and $350 \mu \mathrm{mol} \mathrm{m} \mathrm{m}^{-2} \mathrm{~s}^{-1}$ in $\mathrm{B}$ and between 250 and $400 \mu \mathrm{mol} \mathrm{m} \mathrm{m}^{-2} \mathrm{~s}^{-1}$ in C. In Punta Grande and Centro Lago these parameters showed even lower values. 

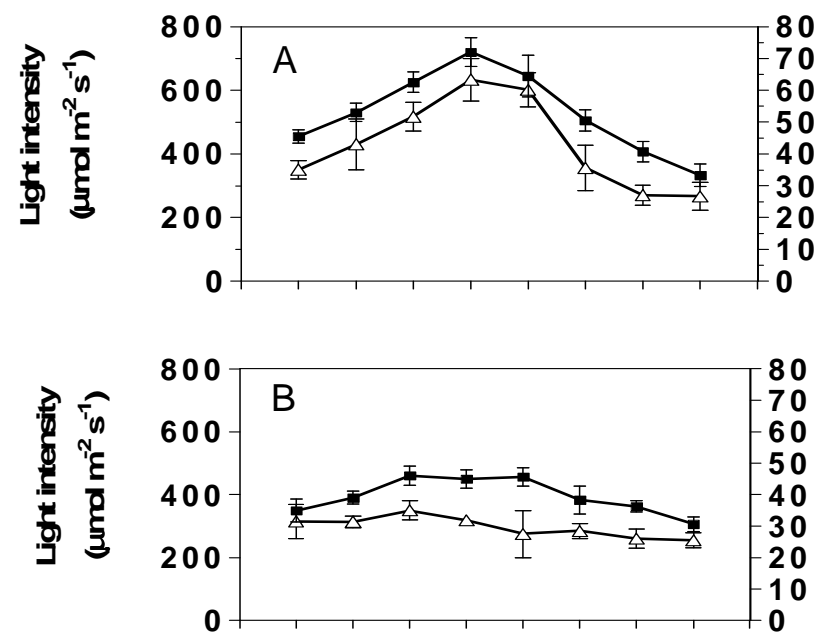

8
8
$\frac{8}{2}$
$\frac{8}{2}$
$\frac{7}{3}$
3
3
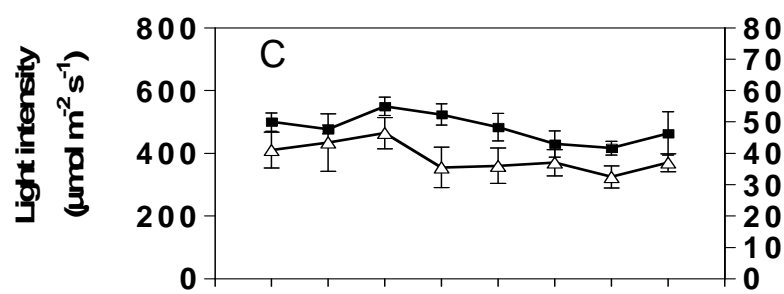

\section{8
$\frac{8}{8}$
$\frac{8}{5}$
$\frac{3}{3}$}
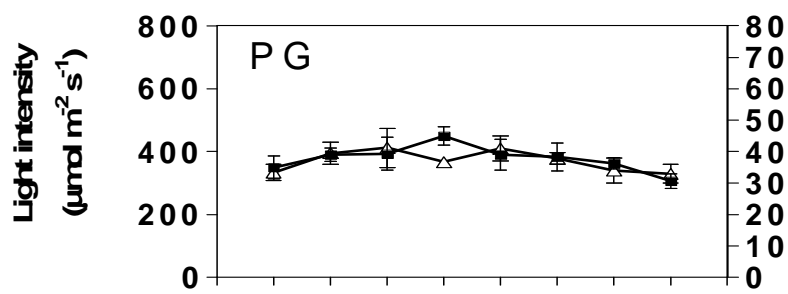

8
8
$\frac{8}{2}$
$\frac{8}{8}$
$\frac{8}{3}$
3
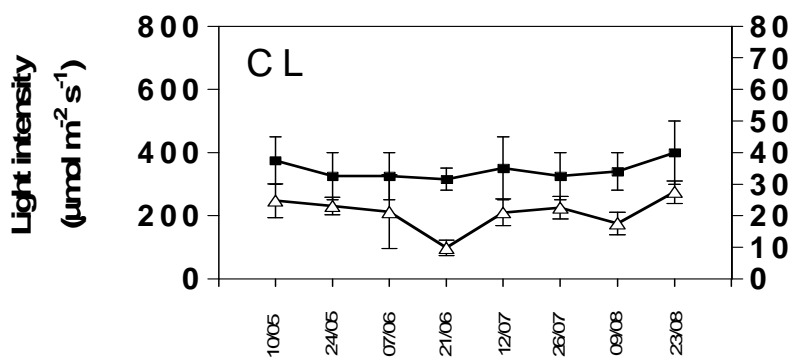

8
8
$\frac{8}{8}$
$\frac{8}{5}$
$\frac{3}{3}$

$\neg$ P.A.R.

$\rightarrow-$ Secchi Depth

sampling date

Figure 4. Trends of Photosynthetic Active Radiation (PAR) and Secchi depth in the three replicated enclosures of $A, B, C$ and two open water sampling sites:

"Punta Grande" (PG), "Centro Lago" (CL) 
The chlorophyll-a content followed the opposite tendency regarding Secchi depth and PAR irradiation. At all the sampling sites chlorophyll decreased during the first two months, to rise again starting from the end of June (Fig. 5). A enclosure replicates showed chlorophyll-a values which were constantly lower than the other stations. The differences of the chlorophyll-a values in A replicates as to B replicates and A replicates as to $C$ replicates were very highly significant ( $p<0.001$, Tukey's test), and significant between A replicates and Centro Lago $(\mathrm{CL})(\mathrm{p}<0.01)$ and A replicates and Punta Grande $(\mathrm{p}<0.05)$.

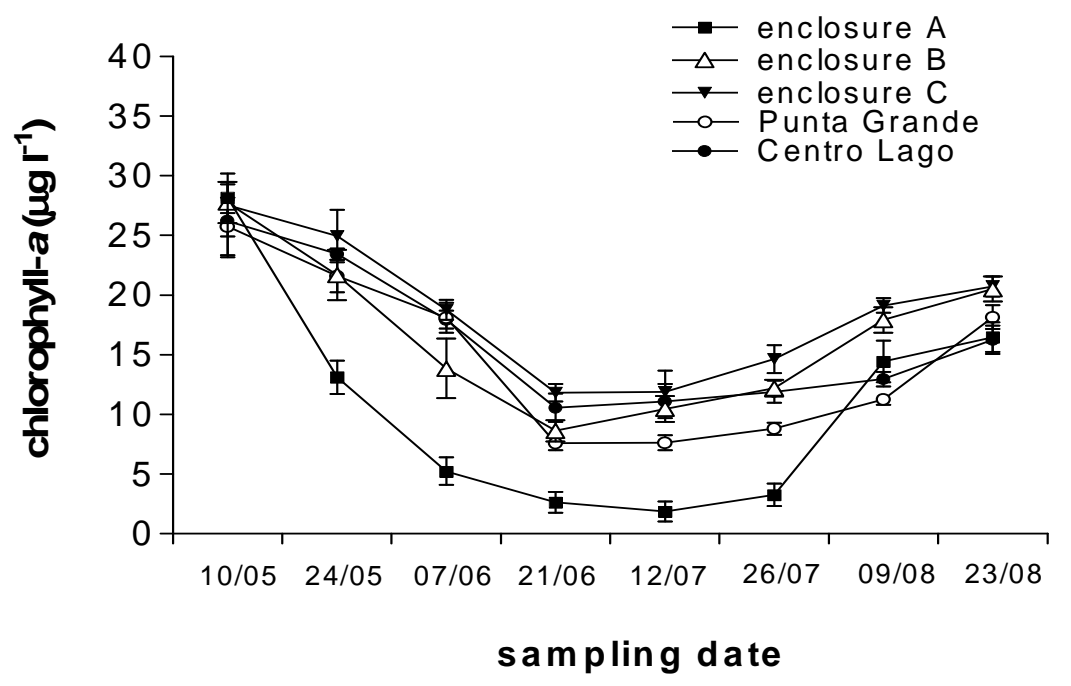

Figure 5. Trends of clorophyll-a content in enclosure replicates water of the five sampling sites; the water analyses were carried out twice a month from May to August.

Data are the averages out of three replicates

The state of PAR radiation in A replicates, shown in Fig. 6, was measured at different depths along the water column. PAR intensity on the surface was constant during the whole trial. The values at $30 \mathrm{~cm}$ depth showed a similar trend to those of Secchi depth and opposite to those of chlorophyll-a, starting from $300 \mu \mathrm{mol} \mathrm{m} \mathrm{s}^{-1}$, reaching a maximum of $600 \mu \mathrm{mol} \mathrm{m} \mathrm{s}^{-1}$ at the end of June and dropping at the end of the experiment to values lower than at the beginning. The PAR radiation at $50 \mathrm{~cm}$ was less variable, and at the lowest levels it remained almost flat, showing no correlation with the clarification of the upper layer.

The physical and chemical parameters of water followed trends that were quite similar among the five stations (Fig. 7), with the exception of water $\mathrm{pH}$ in Centro Lago (CL), which was constantly higher than the other sites during the whole year.

\section{Discussion}

The in vitro experiment showed different growth responses at the same light levels according to the different medium used. These results are meaningful if we explain them on the basis of the chemical analyses of water and sediments from the different locations: in fact the water and sediment chemistry of Centro Chiaro (CC) and Centro Lago (CL) are contrasting (Table 1). Water from CC shows the lowest nutrient levels, while its sediment is the richest one, especially for total $\mathrm{N}(20.39 \mu \mathrm{g} 1-1$ in water against 
$696.08 \mu \mathrm{g} \mathrm{l}^{-1}$ in sediment). Since CC is a closed shallow area surrounded by close emerged vegetation, the low nutrient levels of its water are in accordance with the action of phytodepuration performed by botanical associations which are typical of peaty soils (Farahbakhshazad et al., 2000; Farahbakhshazad and Morrison, 2003), e.g. Phragmites australis (Cav.) Trin., Cladium mariscus L., Typha angustifolia L.

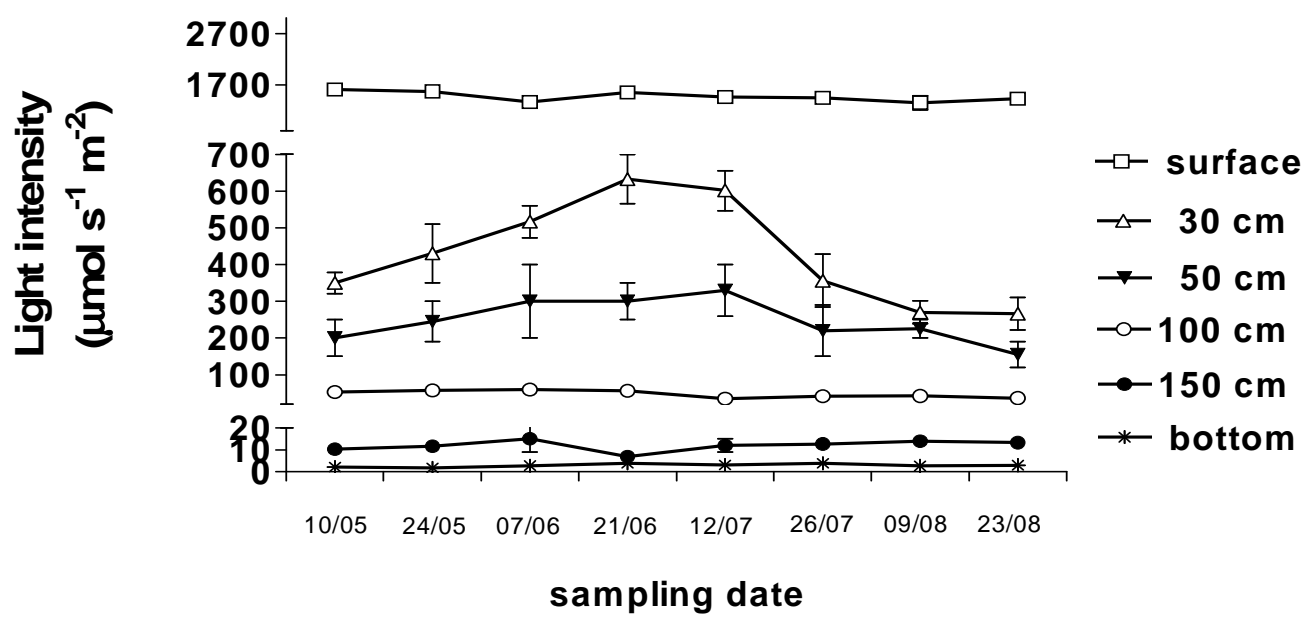

Figure 6. Intensity of PAR radiation at different depths in A enclosure replicates; the analyses were carried out twice a month from May to August

On the other hand, the high nutrient levels of the Centro Chiaro sediment are due to the accumulation of organic matter deriving from the degradation of plant residues which naturally sink to the bottom, as well as the organic matter deriving from the submerged vegetation which was present until some years ago. This shows that the different chemistry causes different growth responses at the same turbidity levels (Bachmann et al. 2002).

The higher dry matter content in plants grown in waters with higher nutrient levels Centro Lago can be evidence of a preferential foliar absorption acted by submerged plants (Brinx, 1997; Wen-Yuan et al., 2004); in fact, the lengthening of plants in the Centro Chiaro, water and sediment, at low light intensities is a symptom of stress. Moreover, since the availability of inorganic carbon has been shown to have a major effect on the interrelationship between light intensity and photosynthesis of submerged macrophytes (Van den Berg et al., 2002), further studies should be carried out to correlate information about $\mathrm{pH}$, alkalinity, calcium content and bicarbonate concentrations of water and sediments with the substantial differences in macrophyte growth when incubated in sediments taken from different parts of a lake.

Considering jointly the results of the two in vitro experiments provides evidence that, at present, the PAR intensity along the water column of the lake is not sufficient to allow the existence of submerged vegetation, particularly near the bottom, where rooting of macrophytes occurs. This phenomenon is due to the turbidity of the lake, caused by a resuspension phenomenon due to the absence of vegetation and by an excessive amount of phytoplankton consequent to eutrophication (Pensabene et al., 1997; Mason, 1997). 
(a)

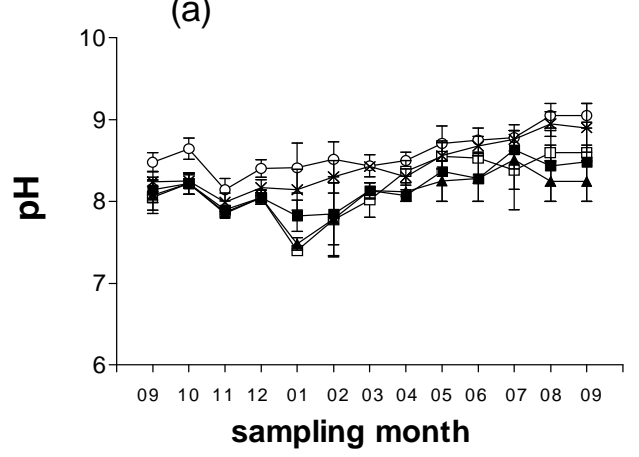

(c)

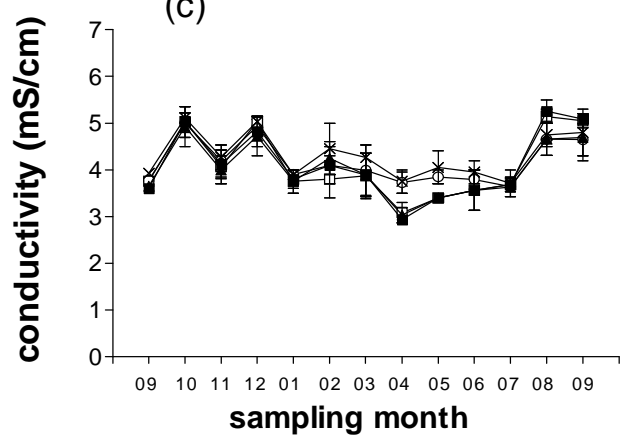

(b)

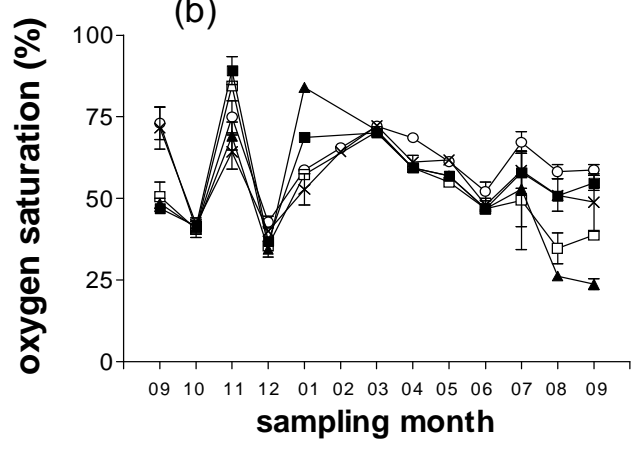

(d)

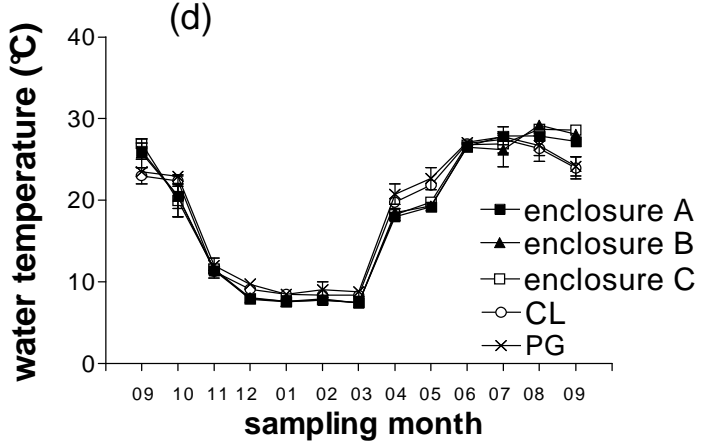

Figure 7. Trends of $\mathrm{pH}(a)$, oxygen saturation (b), conductivity (c) and water temperature (d) at the investigates sites of the Lake, during one year from September to September The months are indicated in abscissa

In the aquaria experiments the different levels of irradiation were simulated at known chemical-physical conditions of water and sediment; the results indicated that the optimal light conditions for growth are, at present, available at about $30 \mathrm{~cm}$ of depth in the lake (Table 2). Since the average depth is $2.5-3 \mathrm{~m}$, this means that the present conditions cannot allow spontaneous recovery of submerged vegetation. According to this evidence it can be seen in what way these values could be reached at the bottom, allowing plant recovery, if higher penetration of light through the water column could be achieved.

The in vivo experiments, showed the positive effect of biomanipulation on the growth of our model species, which was able to grow even at $1.5 \mathrm{~m}$ depth, although the scarceness of light present caused abnormal lengthening. The increase in length combined with a low weight increase at low light conditions indicates shoot elongation to be a valid strategy activated by $M$. verticillatum to compensate conditions of light scarcity. This indicates $M$. verticillatum as being particularly fit for the primary colonization of the bottom of turbid lakes (Ciurli et al., 2008). This species provides a first clarification of the water column and allows the subsequent setting of plants such as Elodea canadensis, which in virtue of their tendency to form dense carpets could provide a stabilization of the bottom in the medium-long term (Ciurli et al., 2008).

We retain that the grazing effect carried out by D. magna (data not shown) together with fish removal caused the phytoplankton population to drop, leading to a remarkable clarification of water in the treated enclosures; evidence of such an effect of clarification carried out by zooplankton has been provided also by other authors 
(Perrow et al., 1994, 1997; Darchambeau et al., 2005). The decline over time of the effect of D. magna, in terms of water clarification, can find an explanation in its seasonal dynamics, especially in the contest of a forced predator-prey system (Scheffer et al., 1997). The disappearance of plants from $C$ enclosure replicates, even on the surface and at $30 \mathrm{~cm}$ depth, provides evidence of an actual difference between in vitro an in vivo conditions, and suggests the concomitant effect in the lake of an additional factor contrasting plant growth, such as an excessive development of epiphyton due to the lack of organisms capable of grazing it in the space of the enclosure (Brönmark, 1985). This factor appears to be fully counterbalanced by D inoculation. Nevertheless, an effective recovery of Massaciuccoli Lake cannot be obtained until an integrated approach, ranging from the reduction of pollutant sources to partial dredging of the sediment, is adopted. The constant nutrient charge, and the long term phosphorus release from the sediment, are in fact a serious obstacle in returning the lake to a clear water state.

Several authors (Van der Does et al., 1992; Kleeberg and Kohl, 1999; Meijer et al., 1999; Søndergaard et al., 2001) have shown the benefits of (partial) dredging the sediment and biomanipulation projects accompanied by $\mathrm{P}$ load reduction to allow the recovery of submerged vegetation. Further long term experiments will be conducted, in particular by removing part of the sediment from inside the enclosures, in order to demonstrate the negative effect of long term nutrient release. Plastic enclosures will be used to prevent the surrounding water from affecting the phosphorus concentration in the above standing water.

Table 3. Mean light intensities (over the year) at different depths in the water column of Massaciuccoli

\begin{tabular}{|c|c|}
\hline Water depth $(\mathbf{c m})$ & Light intensity $\left(\boldsymbol{\mu} \mathbf{m o l ~ s}^{-\mathbf{1}} \mathbf{~ m}^{-\mathbf{2}}\right)$ \\
\hline Surface & 120 \\
\hline 15 & 54 \\
\hline 30 & 30 \\
\hline $50-60$ & 20 \\
\hline 100 & 2 \\
\hline 150 & 0 \\
\hline $250-300$ & 0 \\
\hline
\end{tabular}

\section{Conclusions}

The aquaria experiments, with water and sediment coming from three different parts of the lake, show the feasibility of macrophyte $M$ verticillatum to grow in controlled conditions.

The minimum threshold of light necessary for the survival of the macrophyte has been characterized in aquaria with sediment resuspension to simulate the natural lake conditions. This device permitted us to reproduce the turbidity at different depth levels, using water and sediment lake.

The mesocosms represented by the enclosures placed in the lake give a realistic, small scale simulation of what can happen on a larger scale if systematic intervention of macrophytes reintroduction were performed. Being $M$. verticillatum the last one to disappear, its partial recovery in the experimental context can represent, on a whole- 
lake scale, the first step to provide adequate conditions for the recovery of the other macrophytic species, in order to restore the equilibrium in the lake ecosystem.

The present situation can not allow spontaneous recovery of aquatic macrophytes because of the insufficient amount of light reaching the bottom; nevertheless, conditions compatible with plant life can be achieved on the medium period if combined interventions aimed at the clarification of the water column are put into action.

Acknowledgements. Thank the Natural Park MSRM Authority and in particular all those who have worked so hard on this project, especially the park guards.

\section{REFERENCES}

[1] APHA (1989): Standard Methods for the Examination of Water and Wastewater. $-20^{\text {th }}$ Edition 1998, American Public Health Association, Washington DC.

[2] Bachmann, R.W., Horsburgh, C.A., Hoyer, M.V., Mataraza, L.K., Canfield, D.E. (2002): Relations between trophic state indicators and plant biomass in Florida lakes. Hydrobiologia 470: 219-234.

[3] Baldaccini, G.N., Ercolini, P., Mattioli, M. (1997): Eutrofizzazione del lago di Massaciuccoli. Composizione ed evoluzione temporale delle comunità zooplanctonica e macrobentonica. - In: Cenni, M. (ed.), Lago di Massaciuccoli: 13 ricerche finalizzate al risanamento, Universitaria Litografica Felici, Pisa. pp. 289-346.

[4] Barbaresi, S., Ghelardi, F. (2001): The invasion of the alien crayfish Procambarus clarkii in Europe, with particular reference to Italy. - Biological Invasions 2: 259-264.

[5] Berklioglu, M., Carvalho, L., Moss, B. (1999): Rapid recovery of a shallow hypertrophic lake following sewage effluent diversion: lack of chemical resilience. - Hydrobiologia 412: 5-15.

[6] Breukelaar, A.W., Lammens, E.H., Klein, R.R., Breteler, J.G.P. (1994): Effects of benthivorous breams (Abramis brama) and carp (Cyprinus carpio) on sediment resuspension and concentrations of nutrients and chlorophyll a. - Freshwater Biology 32: 113-121.

[7] Brinx, H. (1997): Do macrophytes play a role in constructed treatment in wetlands? Water Science and Technology 35: 11-17.

[8] Brönmark, C. (1985): Interactions between macrophytes, epiphytes and herbivores: an experimental approach. - Oikos 45: 26-30.

[9] Brunelli, G., Cannicci, G. (1942): Il lago di Massaciuccoli. - Bollettino Pesca Piscicultura Idrobiologia 46: 5-63.

[10] Carpenter, S.R., Lodge, D.M. (1986): Effects of submersed macrophytes on ecosystem processes. - Aquatic Botany 26: 341-370.

[11] Ceccarelli, N., Piaggesi, A., Ciurli, A., Alpi, A. (1997): Residui di diserbanti nelle acque del Lago di Massaciuccoli: Effetti tossici sulle macrofite acquatiche e analisi delle concentrazioni. - In: Cenni, M. (ed.), Lago di Massaciuccoli: 13 ricerche finalizzate al risanamento, Universitaria Litografica Felici, Pisa. pp. 181-202.

[12] Ciurli, A., Alpi, A. (1999): Valutazioni sulle capacità di ripresa delle macrofite acquatiche: limiti e certezze. - In: ARPAT (Agenzia Regionale Protezione Ambientale Toscana) (ed.), Il risanamento del lago di Massaciuccoli, Edizioni ARPAT, Pisa. pp. 169184.

[13] Ciurli, A., Zuccarini, P., Alpi, A. (2008): Growth and nutrient absorption of two submerged aquatic macrophytes in mesocosmos, for reinsertion in a eutrophicated shallow lake. - Wetlands Ecology and Management 17: 107-115.

[14] Cuppen, J.G.M., Van den Brink, P.J., Vann der Woude, H., Zwaardemaker, N., Brock, T.C.M. (1997): Sensitivity of macrophyte-dominated freshwater microcosms to chronic 
levels of the herbicide linuron. II. Community metabolism and invertebrates. Ecotoxicology and Environmental Safety 38: 25-35.

[15] Darchambeau, F., Thys, I., Leporcq, B., Hoffmann, L., Descy, J.P. (2005): Influence of zooplankton stoichiometry on nutrient sedimentation in a lake system. - Limnology and Oceanography 50: 905-913.

[16] De Melo, R., France, R., McQueen, D.J. (1992): Biomanipulation: Hit or myth? Limnology and Oceanography 37: 192-207.

[17] Drenner, R.W., Hambright, K.D. (1999): Review: Biomanipulation of fish assemblages as a lake restoration technique. - Archiv für Hydrobiologie 146: 129-165.

[18] Farahbakhshazad, N., Morrison, G.M. (2003): Phosphorus removal in vertical upflow constructed wetland system. - Water Science and Technology 48: 43-50.

[19] Farahbakhshazad, N., Morrison, G.M., Salati Filho, E. (2000): Nutrient removal in a vertical upflow wetland in Piracicaba, Brazil. - Ambio 29: 74-77.

[20] Gherardi, F., Baldaccini, G.N., Barbaresi, S., Ercolini, P., De Luise, G., Mazzoni, D., Mori, M. (1999): Alien cryfish: the situation of Italy. - Crustacean Issues 11: 107-128.

[21] Haney, J.F. Hall, D.J. (1973): Sugar-coated Daphnia: a preservation technique for Cladocera. - Limnology and Oceanography 18: 331-333.

[22] Hansson, L.A., Annadotter, H., Bergman, E., Hamrin, S.F., Jeppesen, E., Kairesalo, T., Luokkanen, E., Nilson, P.A., Søndergaard, M. (1999): Biomanipulation as an application of food chain theory: constraints, synthesis and recommendations for temperate lakes. Ecosystems 1: 13-23.

[23] Harper, D. (1992): What is eutrophication? - In: Chapman \& Hall (eds), Eutrophication of freshwater: principles, problems and restoration, Chapman \& Hall, London. Pp 1-128.

[24] Havens, K.E. (1993): Responses to experimental fish manipulation in a shallow, hypertrophic lake: The relative importance of benthic nutrient cycling and trophic cascade. - Hydrobiologia 254: 72-80.

[25] Hosper, S.H., Meijer, M.L. (1993): Biomanipulation, will it work for your lake. A simple test for the assessment of chances for clear water, following drastic fish-stock reduction in shallow eutrophic lakes. - Ecological Engineering 2: 63-72.

[26] Hosper, S.H. (1997): Clearing Lakes. An ecosystem approach to the restoration and management of shallow lakes in The Netherlands. - PhD Thesis, Agricultural University, Wageningen.

[27] Hosper, S.H., Meijer, M.L., Gulati, R.D., Van Donk, E. (2005): Biomanipulation in shallow lakes: concepts, case studies and perspectives. - In: O'Sullivan, P. E. and Reynolds, C. S. (eds.), The lakes handbook. Volume 2: lake restoration and rehabilitation. Blackwell Publishing.

[28] Jeppesen, E., Søndergaard, M., Mortensen, E., Jensen, J., Kristensen, P., Riemann, B., Jensen, H.J., Muller, J.P., Sortkjær, O,. Christoffersen, K., Bosselmann, S., Dall, E. (1990): Fish manipulation as a restoration tool in shallow, eutrophic temperate lakes 1: cross-analysis of three Danish case studies. - Hydrobiologia 200/201: 205-208.

[29] Jeppesen, E., Søndergaard, M., Søndergaard, M., Christoffersen, K. (1997): The structuring Role of Submerged Macrophytes in Lakes. - Springer, New York.

[30] Kleeberg, A., Kohl, J.G. (1999): Assessment of the long-term effectiveness of sediment dredging to reduce benthic phosphorus release in shallow Lake Müggelsee (Germany). Hydrobiologia 394: 153-161.

[31] Krause-Jensen, D., Greve, T.M., Nielsen, K. (2005): Eelgrass as a Bioindicator Under the European Water Framework Directive. - Water Resources Management 19: 63-75.

[32] Lau, S.S., Lane, S.N. (2001): Continuity and change in environmental systems: the case of shallow lake ecosystems. - Progress in Physical Geography 25: 178-201.

[33] Lauridsen, T.L., Pedersen, L.J., Jeppesen, E., Søndergaard, M. (1996): The importance of macrophyte bed size for cladoceran composition and horizontal migration in a shallow lake. - Journal of Plankton Research 18: 2283-2294. 
[34] Lennox, L.J. (1984): Sediment-water exchange in Lough Ennell with particolar reference to phosphorus. - Water research 18: 1483-1485.

[35] Mason, C.F. (1997): Massaciuccoli Lake - trophic status and a review of possibile solutions. - In: Cenni, M. (ed.), Lago di Massaciuccoli: 13 ricerche finalizzate al risanamento, Universitaria Litografica Felici, Pisa. pp. 379-388.

[36] Meijer, M.L., De Boois, I., Scheffer, M., Portielje, R., Hosper, H. (1999): Biomanipulation in shallow lakes in The Netherlands: an evaluation of 18 case studies. Hydrobiologia 408/409: 13-30.

[37] Meijer, M.L., Van Nes, E.H., Lammens, E.H.R.R., Gulati, R.D., Grimm, M.P., Backx, J.J.G.M., Hollebeek, P., Blaauw, E.M., Breukelaar, A.W. (1994): The consequences of a drastic fish stock reduction in the large and shallow Lake Wolderwijd, The Netherlands. Can we understand what happened? - Hydrobiologia 275/276: 31-42.

[38] Moss, B., Madgwick, J., Phillips, G. (1996a): A guide to the restoration of nutrient enriched shallow lakes. - Environment Agency, Norwich.

[39] Mulderij, G., Mooij, W.M., Van Donk, E. (2005): Allelopathic growth inhibition and colony formation of the green alga Scenedesmus obliquus by the aquatic macrophytes Stratiotes aloides. - Aquatic Ecology 39: 11-21.

[40] Mulderij, G., Van Donk, E., Roelofs, J.G.M. (2003): Differential sensitivity of green algae to allelopathic substances from Chara. - Hydrobiologia 491: 261-271.

[41] Mulderij, G., Van Nes, E.H., Van Donk, E. (2007): Macrophyte-phytoplankton interactions: the relative importance of allelopathy versus other factors. - Ecological modelling 204: 85-92.

[42] Nichols, S.A., \& Buchan, L. A. J. (1997): Use of Native Macrophytes as Indicators of Suitable Eurasian Watermilfoil Habitat in Wisconsin Lakes. - Journal of Aquatic Plant Management 35: 21-24.

[43] Pedreschi, L. (1956): Il lago di Massaciuccoli e il suo territorio. - Memorie della Società Geografica Italiana 27: 1-225.

[44] Pensabene, G., Frasari, F., Cini, C. (1997): Valutazione quantitativa del carico di nutrienti e di solidi sospesi immesso nel lago di Massaciuccoli dai comprensori di bonifica di Vecchiano e Massaciuccoli. - I: Cenni, M. (ed.), Lago di Massaciuccoli: 13 ricerche finalizzate al risanamento, Universitaria Litografica Felici, Pisa. pp. 131-148.

[45] Perrow, M.R., Moss, B., Stansfield, J. (1994): Trophic interactions in a shallow lake following a reduction in nutrient loading - A long-term study. - Hydrobiologia 276: 4352.

[46] Perrow, M.R., Meijer, M.L., Dawidowicz, P., Coops, H. (1997): Biomanipulation in shallow lakes: state of art. - Hydrobiologia 342/343: 355-365.

[47] Petrini, C., Bazzocchi, R., Moretti, A. (1996): La fitodepurazione. - Agricultura 2: 12-14.

[48] Phillips, G., Jackson, R., Bennett, C., Chilvers, A. (1994): The importance of sediment phosporus release in the restoration of very shallow lakes (the Norfolk Broads, England) and implications for biomanipulation. - Hydrobiologia 275/276: 445-456.

[49] Pitt, J.A., Kelly, A., Phillips, G.L. (1997): Control of nutrient release from sediments. In: Madwick, F.J. \& Phillips, G.L. (eds.), Restoration of the Norfolk Broads - Final Report, Broads Authority and Environment Agency, Norwich.

[50] R Development Core Team (2005): R: A language and environment for statistical computing, R Foundation for Statistical Computing, Vienna.

[51] Rose, C., Crumpton, W.G. (1996): Effects of emergent macrophytes on dissolved oxygen dynamics in a prairie pothole wetland. - Wetlands 16: 495-502.

[52] Scheffer, M. (1998): Ecology of Shallow Lakes, Chapman \& Hall, London.

[53] Scheffer, M., Hosper, S.H., Meijer, M.L., Moss, B., Jeppesen, E. (1993): Alternative equilibria in shallow lakes. - Tree 8: 275-279.

[54] Scheffer, M., Portielje, R, Zambiano, L. (2003): Fish facilitate wave resuspension of sediment. - Limnology and Oceanography 48: 1920-1926. 
[55] Scheffer, M., Rinaldi, S., Kuznetsov, Y.A., Van Nes, E.H. (1997): Seasonal dynamics of Daphnia and algae explained as a periodically forced predator-prey system. - Oikos 80: 519-532.

[56] Schutten, J., Dainty, J., Davy, A.J. (2005): Root anchorage for submerged plants in shallow lakes. - Journal of Ecology 93: 556-571.

[57] Shapiro, J., Lamarra, V. Lynch, M. (1975): Biomanipulation: an ecosystem approach to lake restoration. - In: Brezonik, P.L., Fox, J.L. (eds.), Proceedings of a symposium on water quality management through biological control, University of Florida, Gainsville. Pp 85-96.

[58] Søndergaard, M., Jensen, J.P., Jeppesen, E. (2001): Retention and internal loading of phosphorus in shallow, eutrophic lakes. - Scientific World Journal 23: 427-442.

[59] Søndergaard, M, Jensen, J.P., Jeppesen, E., Møller, P.H. (2002): Seasonal dynamics in the concentrations and retention of phosphorus in shallow Danish lakes after reduced loading. - Aquatic Ecosystem Health and Management 5: 19-29.

[60] Tomei, P.E., Guazzi, E., Barsanti, A. (1997): La carta della vegetazione delle paludi e del lago di Massaciuccoli. - In: Cenni, M. (ed.), Lago di Massaciuccoli: 13 ricerche finalizzate al risanamento, Universitaria Litografica Felici, Pisa. pp. 275-288.

[61] Tonno, I., Kunnap, H., Noges, T. (2003): The role of zooplankton grazing in the formation of "clear water phase" in a shallow charophyte-dominated lake. Hydrobiologia 506: 353-358.

[62] Vaithiyanathan, P., Richardson, C.J. (1997): Nutrient profiles in the everglades: examination along the eutrophication gradient. - The Science of the Total Environment 205: 81-95.

[63] Van den Berg, M.S., Coops, H., Simons, J., Pilon, J. (2002): A comparative study of the use of inorganic carbon resources by Chara aspera and Potamogeton pectinatus. Aquatic Botany 72: 219-233.

[64] Van der Does, J., Verstraelen, P., Boers, P.,Van Roestel, J., Roijackers, R., Moser, G. (1992): Lake restoration with and without dredging of phosphorus-enriched upper sediment layers. - Hydrobiologia 233: 197-210.

[65] Van Donk, E., \& Van de Bund, W. J. (2002): Impact of submerged macrophytes including charophytes on phyto- and zooplankton communities: allelopathy versus other mechanisms. - Aquatic Botany 72: 261-274.

[66] Wen-Yuan, K., Chun-Sheng, L., Yih-Chi, C. (2004): Foliar nutrient dynamics of five dominant plant species in Yuanyang Lake Nature Preserve, Taiwan. - Taiwania 49: 4956. 